France. ${ }^{11} \mathrm{AP}-\mathrm{HP}$, Groupe Hospitalier Pitié-Salpêtrière Charles Foix, Service de Pneumologie et Réanimation Médicale, Paris, France. ${ }^{12}$ Both authors contributed equally.

Correspondence: Gilles Garcia, AP-HP, Hôpital Universitaire de Bicêtre, Service d'Explorations Fonctionnelles Respiratoires, Centre de Référence de l'Hypertension Pulmonaire Sévère, DHU TORINO "Thorax Innovation", 78 Rue du Général Leclerc, 94270, Le Kremlin-Bicêtre, France. E-mail: gilles.garcia@bct.aphp.fr

Received: March 212014 | Accepted after revision: June 282014 | First published online: Aug 202014

Conflict of interest: None declared.

Acknowledgements: Some of the results of this study have been previously reported in the form of an abstract for which P. Laveneziana was the recipient of the Young Investigator Award at the fifth World Symposium on Pulmonary Hypertension, which was held in Nice, France, from February 27 to March 1, 2013.

\title{
References
}

1 Montani D, Achouh L, Dorfmuller P, et al. Pulmonary veno-occlusive disease: clinical, functional, radiologic, and hemodynamic characteristics and outcome of 24 cases confirmed by histology. Medicine (Baltimore) 2008; 87: 220-233.

2 Montani D, Price LC, Dorfmuller P, et al. Pulmonary veno-occlusive disease. Eur Respir J 2009; 33: 189-200.

3 McLaughlin VV, Badesch DB, Delcroix M, et al. End points and clinical trial design in pulmonary arterial hypertension. J Am Coll Cardiol 2009; 54: Suppl., S97-S107.

4 Laveneziana P, Garcia G, Joureau B, et al. Dynamic respiratory mechanics and exertional dyspnoea in pulmonary arterial hypertension. Eur Respir J 2013; 41: 578-587.

5 Laviolette L, Laveneziana P. Dyspnoea: a multidimensional and multidisciplinary approach. Eur Respir J 2014; 43: $1750-1762$.

6 Badesch DB, Champion HC, Sanchez MA, et al. Diagnosis and assessment of pulmonary arterial hypertension. J Am Coll Cardiol 2009; 54: Suppl., S55-S66.

7 Galie N, Hoeper MM, Humbert M, et al. Guidelines for the diagnosis and treatment of pulmonary hypertension. Eur Respir J 2009; 34: 1219-1263.

8 Eyries M, Montani D, Girerd B, et al. EIF2AK4 mutations cause pulmonary veno-occlusive disease, a recessive form of pulmonary hypertension. Nat Genet 2014; 46: 65-69.

9 Simonneau G, Robbins IM, Beghetti M, et al. Updated clinical classification of pulmonary hypertension. J Am Coll Cardiol 2009; 54: Suppl., S43-S54.

10 Borg GA. Psychophysical bases of perceived exertion. Med Sci Sports Exerc 1982; 14: 377-381.

11 Trip P, Girerd B, Bogaard HJ, et al. Diffusion capacity and BMPR2 mutations in pulmonary arterial hypertension. Eur Respir J 2014; 43: 1195-1198.

12 Miura A, Akagi S, Nakamura K, et al. Different sizes of centrilobular ground-glass opacities in chest high-resolution computed tomography of patients with pulmonary veno-occlusive disease and patients with pulmonary capillary hemangiomatosis. Cardiovasc Pathol 2013; 22: 287-293.

13 Sun XG, Hansen JE, Oudiz RJ, et al. Exercise pathophysiology in patients with primary pulmonary hypertension. Circulation 2001; 104: 429-435.

\section{The concept of control in COPD: a new proposal for optimising therapy}

\section{To the Editor:}

Chronic obstructive pulmonary disease (COPD) is a very heterogeneous disease and therefore treatment should be individualised considering the different clinical characteristics and severity of each patient [1-3]. In an attempt to identify individuals with similar characteristics and response to treatment, a group of experts has defined the "clinical phenotypes" of COPD as those attributes of the disease alone or in combination that "describe differences between individuals with COPD in relation to parameters that have clinical significance (symptoms, exacerbations, response to treatment, rate of progression disease, or death)" [4]. Therefore, the clinical phenotype should be able to classify patients into subgroups with prognostic value and to determine the most appropriate therapy to achieve better results from a clinical standpoint.

However, even patients with similar clinical characteristics and degree of airflow obstruction may have a different expression of their disease or present with short-term changes in their state that may require changes in treatment. Therefore, the new concept of disease control, similar to the "control of asthma" concept should be added in the assessment of patients with COPD. But, what is control in COPD? 
Control is a new dimension in the evaluation of patients with COPD, after the evaluation of symptoms, comorbidities and the degree of severity based either on the impairment in lung function or on any multidimensional prognostic indices. Control is a dynamic concept; as an example, two patients who are the same age, have the same level of symptoms and same level of airflow obstruction, with two exacerbations in the current year, may have different degrees of clinical control. One of the patients may have had four exacerbations in the previous year and so comparatively control has improved, whereas the second patient may have had no exacerbations the previous year and therefore has lost control. Even if a clinical evaluation of both patients, taking into consideration the current situation, would have led to similar conclusions, it is clear that the treatment strategy should differ in both cases based on assessment of the previous history of events. Therefore, there is a need to include criteria which define the current clinical situation of the patient and, at the same time, consider the short-term evolution of the disease.

The proposal of control in COPD includes two components: impact and stability. Impact refers to the current clinical situation, and consists of a cross-sectional assessment corresponding to a specific time point (i.e. "How are you today?"). In addition, the evolution of this clinical impact is a dynamic term that expects to capture significant clinical changes and therefore requires at least two observations over time. This component is framed within the concept of stability ("How are you compared with the last visit?"). From the interaction of these two concepts of impact and stability, a new dimension is derived which we will denominate "control of COPD" (fig. 1).

The concepts of impact and severity are somewhat related but are not necessarily the same. The level of severity is useful in the initial assessment of the patient and assesses the future risk of death and other complications $[5,6]$, and impact refers to the current repercussion the disease has on the patient. As an example, there are patients with a different degree of dyspnoea or impairment in health-related quality of life for the same level of severity defined by either forced expiratory volume during the first second (FEV1) or even by the BODE (body mass index, airflow obstruction, dyspnoea and exercise capacity) index [7].

Impact can be classified as low or high and should always be adjusted for the level of disease severity since, for example, it would be very unlikely for a patient with very severe COPD to have an excellent health status. We propose that the determination of impact must include assessment of a) the degree of dyspnoea, b) the use of rescue medication, c) limitations in daily activities, and d) sputum colour. Questionnaires of clinical control, such as the COPD Assessment Test (CAT) [8] or the Clinical COPD Questionnaire (CCQ) may be used as an alternative or complementary measure to clinical evaluation [9].

CCQ or CAT scores may significantly differ in patients within the same level of COPD severity, and these scores are sensitive to changes in health status after an exacerbation or intervention $[10,11]$. Together with the simplicity and ease of use of these questionnaires, they are ideal tools to assess clinical impact.

The cut-off values of the different components of the impact evaluation have to be formally validated, but in severe patients $(\mathrm{FEV} 1<50 \%$ or BODE $>5$ ) we should expect a dyspnoea degree of 2 or less, a maximum of

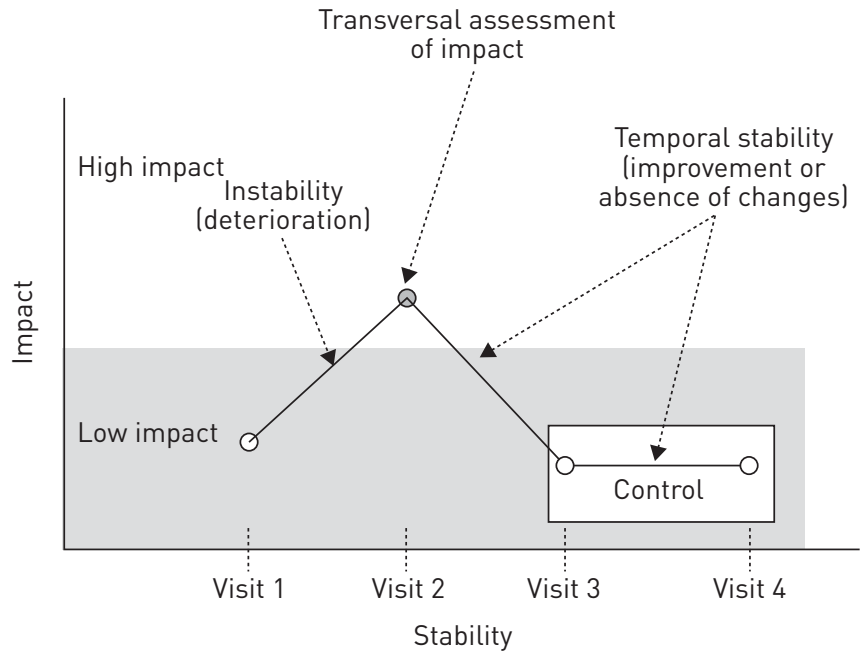

FIGURE 1 Representation of the concept of impact, stability and control in chronic obstructive pulmonary disease. The circles represent the transversal measurement of the clinical situation at different time points (impact); the lines show the analysis of the changes (stability) and the shaded area marks the concept of control, understood as the desirable situation in which a condition of low clinical impact is maintained over a long period of time according to the severity of the disease. 
two inhalations of rescue medication a day, more than 30 mins a day of physical activity (walking) and no production of sputum or scarce production of white sputum; alternatively a CAT score $<20$ or CCQ score $<2$ would be required before we can determine that the disease has a low impact in the patient.

How can stability be evaluated? A stable condition is defined as one that is firm, steady or not easily moved, upset or changed. By translating this definition to our setting, we propose that stability is a situation that remains without significant changes over a period of time or which returns to the previous state after an alteration (exacerbation).

According to this definition and to adequately establish the clinical stability of a patient with COPD the following two criteria must be fulfilled: a) absence of exacerbation; b) absence of significant clinical worsening during the period of observation; i.e. this concept includes the absence of significant clinical deterioration or the presence of improvement.

The CAT or CCQ may also be potentially useful to evaluate clinical changes over time $[10,11]$. In the case of the CAT it has been described that a change of greater than 2 points may indicate clinically significant deterioration [12], with the same occurring with a change greater than 0.4 points for the CCQ [13].

Therefore, disease control is defined by low impact and stability and the following criteria should be fulfilled: 1) low clinical impact adjusted to the level of severity of the disease, and 2) stability defined by the absence of significant clinical worsening and by the absence of exacerbations during the observation period.

Ideally, an adequate clinical control should: 1) be related to less biological activity of the disease; 2) be associated with better clinically relevant outcomes; and 3) be able to be modified by the treatment, that is, the therapeutic objective involves seeking clinical control.

Patients classified as non-controlled should be evaluated more in depth in search of the possible causes (persistence in smoking habits, bad inhalatory technique, poor treatment compliance, comorbidity, chronic bronchial infection, exacerbations, etc.). On other occasions in which the cause is not identified or the correction of the cause is not sufficient, the best option is to add or increase the maintenance medication and/or consider other non-pharmacological options such as respiratory rehabilitation or oxygen therapy.

Our concept of control of COPD is simpler than the control panel proposed by AGUSTI and MACNEE [1]. They proposed a complex assessment including severity, impact and activity, with variables such as full lung function, exercise capacity and biomarkers. All these variables could be integrated in a hand-held device that would provide an estimate of the control of the disease. This approach may provide a more comprehensive and personalised evaluation of the patient, but while it is available, the clinical control integrating impact and stability based on findings obtained in the daily clinical visit can be of help in everyday practice.

We suggest that determining the clinical control of the patient with COPD be used as a measure which complements the evaluation of the clinical phenotype and the level of severity of the disease, as proposed in the Spanish Guidelines for COPD (GesEPOC), which represent a model of transition towards individualised medicine [14]. Phenotype and severity must be determined at the first visit and guide the initial therapy. In subsequent visits, other than those made during periods of exacerbation, the evaluation of control, including assessment of impact and stability, should help physicians to make therapeutic decisions to increase or decrease the intensity of treatment.

0 @ERSpublications

Control in COPD is a new concept that includes impact and stability and should help to make therapeutic decisions in clinical practice http://ow.ly/yKuIV

Juan José Soler-Cataluña ${ }^{1,2}$, Bernardino Alcázar-Navarrete ${ }^{3}$ and Marc Miravitlles ${ }^{2,4}$

${ }^{1}$ Pneumology Dept, Hospital Arnau de Vilanova, Valencia, Spain. ${ }^{2}$ CIBER de Enfermedades Respiratorias (CIBERES).

${ }^{3}$ Respiratory Dept, Hospital de Alta Resolucion, Loja, Granada, Spain. ${ }^{4}$ Pneumology Dept, Hospital Universitari Vall d'Hebron, Barcelona, Spain.

Correspondence: Marc Miravitlles, Pneumology Dept, Hospital Universitary Vall d'Hebron, P. Vall d'Hebron 119-129, 08035 Barcelona, Spain. E-mail: mmiravitlles@vhebron.net

Received: Feb 252014 | Accepted after revision: May 202014 | First published online: July 242014

Conflict of interest: Disclosures can be found alongside the online version of this article at erj.ersjournals.com

\section{References}

Agusti A, MacNee W. The COPD control panel: towards personalised medicine in COPD. Thorax 2013; 68: 687-690. Miravitlles M, Soler-Cataluña JJ, Calle M, et al. Treatment of COPD by clinical phenotypes: putting old evidence into clinical practice. Eur Respir J 2013; 41: 1252-1256. 
3 McDonald V, Higgins I, Wood LG, et al. Multidimensional assessment and tailored interventions for COPD: respiratory utopia or common sense? Thorax 2013; 68: 691-694.

4 Han MK, Agusti A, Calverley PM, et al. Chronic obstructive pulmonary disease phenotypes: the future of COPD. Am J Respir Crit Care Med 2010; 182: 598-604.

5 Celli BR, Cote CG, Marín JM, et al. The body-mass index, airflow obstruction, dyspnea, and exercise capacity index in chronic obstructive pulmonary disease. N Engl J Med 2004; 350: 1005-1012.

6 Soler-Cataluña JJ, Martínez-García MA, Sánchez L, et al. Severe exacerbations and BODE index: two independent risk factors for death in male COPD patients. Respir Med 2009; 103: 692-699.

7 Agustí A, Calverley PMA, Celli B, et al. Characterisation of COPD heterogeneity in the ECLIPSE cohort. Respir Res 2010; 11: 122

8 Jones PW, Harding G, Berry P, et al. Development and first validation of the COPD Assessment Test. Eur Respir J 2009; 34: 648-654.

9 Van der Molen T, Willemse BWM, Schokker S, et al. Development, validity and responsiveness of the clinical COPD questionnaire. Health Qual Life Outcomes 2003; 1: 13.

10 Agustí A, Soler JJ, Molina J, et al. Is the CAT questionnaire sensitive to changes in health status in patients with severe COPD exacerbations? COPD 2012; 9: 492-498.

11 Miravitlles M, García-Sidro P, Fernández-Nistal A, et al. Course of COPD assessment test (CAT) and clinical COPD questionnaire (CCQ) scores during recovery from exacerbations of chronic obstructive pulmonary disease. Health Qual Life Outcomes 2013; 11: 147.

12 Kon SSC, Canavan JL, Jones SE, et al. Minimum clinically important difference for the COPD Assessment Test: a prospective analysis. Lancet Respir Med 2014; 2: 195-203.

13 Kocks JWH, Tuinenga MG, Uil SM, et al. Health status measurement in COPD: the minimal clinically important difference of the clinical COPD questionnaire. Respir Res 2006; 7: 62.

14 Miravitlles M, Soler-Cataluña JJ, Calle M, et al. Spanish COPD guidelines (GesEPOC). Pharmacological treatment of stable COPD. Arch Bronconeumol 2012; 48: 247-257.

\section{Rhinovirus infection in young children is associated with elevated airway TSLP levels}

To the Editor:

Rhinovirus wheezing illnesses during early childhood are strongly linked with development of asthma later in life [1]. Indeed, rhinovirus infection in the first 3 years of life is associated with an almost 10-fold increase in risk for asthma at age 6 years [1]. The exact mechanism by which rhinovirus elicits a proasthmatic propensity in young children is largely unknown, but is purportedly related to a viral-induced T-helper cell (Th)2 airway inflammatory response [2]. Interestingly, the discovery of interactions between epithelial innate immunity and adaptive allergic responses has unveiled new potential links between rhinovirus and asthma. Of particular interest is the epithelial-derived cytokine thymic stromal lymphopoietin (TSLP), which is considered a "master Th2 cytokine" because it primes the differentiation of naive T0 cells into Th2 lymphocytes via activation of antigen presenting cells [3]. TSLP is induced by rhinovirus infection or by exposure to double stranded (ds)RNA (viral surrogate) in the lungs of allergic mice [4], and in human bronchial epithelial cells (HBEC) [5]. Together, these data suggest that TSLP may be the missing link between innate antiviral epithelial immunity and the Th2 immune response characteristic of asthma.

This cross-sectional preliminary study aimed to investigate whether rhinovirus infections that occur naturally during the first 3 years of life are associated with elevated airway TSLP levels and enhanced Th2 responses, which may potentially facilitate the establishment of rhinovirus-induced pro-asthmatic changes during early childhood. We measured nasal airway TSLP, Th2 cytokines and antiviral responses in nasal washes obtained from newborns, infants and toddlers ( $\leqslant 3$ years) with PCR-confirmed acute rhinovirus infection $(n=71)$ relative to age-matched subjects without detectable virus using the PCR panel $(n=54)$. Nasal airway secretions were collected from children aged $\leqslant 3$ years seen in our medical centre (from February to December 2013) at the onset of acute respiratory illnesses by nasal saline lavage. The median (interquartile range) age of subjects was $0.58(0.15-0.83)$ years in the control group and $0.99(0.48-1.65)$ years in the rhinovirus group. There were no significant differences in the baseline demographic characteristics of the study groups, including ethnicity and sex. Nasal samples were analysed by a viral multiplex PCR kit (Luminex, TX, USA) for 14 targets used for clinical purposes in our institution according 